\title{
Mensaje italiano desde el futuro
}

\section{Italian message from the future}

Señor Editor,

Muchos en Chile aun no pueden imaginar como la pandemia global COVID-19 causada por el coronavirus SARS-CoV-2 podría cambiar sus vidas. En el norte de Italia, no hay necesidad de utilizar la imaginación. Los ataúdes se acumulan en iglesias y cementerios, mientras continua la prohibición de realizar funerales. Los hospitales están colapsados; el $80 \%$ de las camas en hospitales estan siendo destinadas al tratamiento de pacientes confirmados de COVID-19. El personal médico se ve enfrentado a la elección devastante de quien debe recibir tratamiento. Aquellos quienes no logran recuperarse, perecen aislados, sin la compañía de sus familias o amigos.

\section{Hecho en Italia}

Italia es una de las naciones más golpeadas por la pandemia COVID-19. Como científico chileno que vive y trabaja en Milán (región de Lombardía, norte de Italia), sigo con atención e incertidumbre las acciones que la autoridad en Chile está poniendo en práctica. Desde la detección de los primeros casos en febrero hasta ahora, he podido advertir varias razones por las que Italia enfrenta un escenario complejo y que pueden ser tenidas en consideración al evaluar la situación en Chile.

1. Italia posee una expectativa de vida, 84 años. Esto significa que gran parte de la población italiana son adultos mayores. En el 2018 el 22,6\% de la población tenía 65 o más años, entre las proporciones más altas de Europa. Gran parte de los contagiados y decesos corresponden justamente a adultos mayores. La comunidad médica ha manifestado que el SARS-CoV-2 representa una seria amenaza para ellos (sobre todo aquellos con enfermedades crónicas) comparado con jóvenes y niños. Milán está localizada en la llanura Padana; es una ciudad cuya polución recuerda a la de Santiago. Esto, si bien aumenta el riesgo en toda la población, resulta particularmente peligroso para los adultos mayores.
2. La población italiana no está habituada al distanciamiento social. Besos, abrazos, cercanía física son comunes entre familiares, amigos y colegas de trabajo. La percepción psicológica-cultural del espacio privado es menor que en otros países. Es así como las reuniones sociales de todo tipo en espacios públicos y privados fueron prohibidas (desde el inicio de marzo de 2020). Al inicio, esta medida fue difícilmente acatada, si no hasta que el número de casos creció dramáticamente, y se decretó el cierre de cafeterías, bares, restaurantes, clubs, discotecas, parques y juegos infantiles. Actualmente, sólo permanecen abiertos al público negocios de alimentos, panaderías y farmacias.

3. Milán, es la capital financiera de Italia; un polo industrial y de negocios. Posee estrechas conexiones comerciales y educacionales con China. La región del norte de Italia alberga diversas corporaciones y compañías multinacionales, con trabajadores-viajeros de todo el mundo. De esta manera, imaginemos una población donde una persona resulta infectada por SARS-CoV-2; ésta lo transmite a otras dos personas. Y cada una de aquellas dos personas infectan a otras dos y así sucesivamente. Podemos prever que el número de personas infectadas aumentará rápidamente. Teniendo en cuenta la facilidad de desplazamiento y la conectividad actual, esto ocurrirá no solo a escala local, también a través del país y del continente. Al 27 de marzo de 2020 sólo China registraba más casos que Italia. Sin embargo, con mucha menos población, la proporción de infectados en Italia es mucho mayor que en China.

\section{Evitar la inacción}

Un factor clave en el manejo de una emergencia sanitaria de este nivel es aprender las lecciones de otros en circunstancias similares. Consideremos la pandemia COVID-19 como caso puntual. Las autoridades de gobierno en Chile y de cualquier otro país tienen dos responsabilidades fundamentales: 1 ) solucionar el problema inmediato, de manera proactiva y decidida, y 2) evitar que se repita en el futuro. 
Tenemos que salvaguardar la vida de las personas, mientras se mejora la respuesta a los brotes epidémicos y catástrofes en general. Basta contrastar como el mundo se prepara para la guerra y como, para combatir una pandemia viral. La OTAN, tiene una fuerza de intervención rápida que se ejercita continuamente para verificar todos los aspectos de una eventual operación militar. No existe algo similar como politica de salud pública. Las estructuras de la organización mundial de salud (OMS), creadas para promover un sistema de alerta y respuesta inmediata carecen de fondos y de personal calificado. Salvo paises como Corea del Sur y Taiwan possen un procedimiento operativo estándar (de la sigla en inglés SOP, standard operating procedure), implementado luego de las epidemias SARS y MERS.

Italia está luchando contra una crisis sin precedentes que desafortunadamente ha encontrado terreno fértil en elementos demográficos, su geografía y por sobre todo la idiosincrasia. Epidemiólogos Chinos que viajaron a Milán a contribuir con su experiencia, manifestaron que las medidas adoptadas por parte del gobierno italiano fueron tardías e insuficientes, como por ejemplo la cuarentena total (con excepción de los trabajos denominados esenciales, como personal sanitario y científico), que solo se aplicó casi un mes despues de los primeros 11 casos confirmados en febrero. Además, se le atribuye al gobierno regional un glamoroso paso en falso; mensajes contradictorios a la población como "Milán no se detiene", legitimaron comportamientos del todo funcionales a la propagación del virus.

En línea con lo anterior, con el fin de detener la pandemia, los gobiernos han establecido diversos enfoques. La aplicación y posterior éxito de éstos dependen fuertemente de los elementos socio-culturales de cada país, tales como las estructuras sociales locales, la coherencia de la comunidad, los métodos de comunicación preferidos y la relación con la autoridad; y podrían ser agrupados en tres tipologías:

a) monitoreo y seguimiento estricto de la gente (Corea del Sur).

b) aislamiento o distaciamiento social y solidaridad global (Italia). c) combinación de ambas (China)

La primera en el contexto de una población como la surcoreana auto-motivada, informada y consciente de los hechos y evidencia científica, a través de canales oficiales, puede ser por lejos la mas útil. Para alcanzar tal nivel de obediencia y cooperación, la población tiene que confiar. La gente necesita confiar en la ciencia, en las autoridades públicas de salud y en la transparencia de la información transmitida por los medios de comunicación. Corea del Sur llevó a cabo una campaña informativa agresiva, muestreos de población a gran escala, cuarentena, búsqueda y seguimiento de personas expuestas a inviduos afectados, tratamiento a aquellos que lo requerían, y desinfección de áreas contaminadas. En apariencia resultan medidas obvias, pero la ejecución correcta de éstas es la que finalmente define su efectividad.

Italia ha adoptado la alternativa del aislamiento social y solidaridad global. La pandemia por si misma y la crisis económica subyacente son problemas globales. Datos del fondo monetario internacional señalan que el mundo ha entrado en recesión, cuya recuperación se proyecta hacia el año 2021. La extensión de ésta depende de dos factores: 1) contención de la pandemia y 2) cooperación global. Es necesario que los países hagan esfuerzos diplomáticos. Que esten dispuestos a compartir e intercambiar informacion abiertamente, a pedir consejos humildemente y confiar en los datos e ideas recibidos. Lo que un médico italiano descubre en Milán podría ayudar a salvar vidas en Santiago de Chile. Paralelamente, es importante la participación activa de la población. Existe evidencia científica que muestra que el SARS-CoV-2 puede ser transmitido por personas asintomáticas, presintomáticas o levemente enfermas (así el uso de mascarillas resultaba fundamental desde el inicio). En Italia, esto pudo suceder y podría estar sucediendo en la actualidad; y explicaría el aumento casi exponencial de los casos de COVID-19 desde el 21 de febrero de 2020 a la fecha. Sin embargo, en la población italiana la confianza en las autoridades políticas como en la ciencia ha sido erosionada durante años. Es cierto, la credibilidad no puede ser restaurada de la noche a la mañana. No obstante, estos no son tiempos normales. En momentos de crisis la mentalidad debe adaptarse rápidamente. Es así como Italia inició una campaña de divulgación cientifica en la que se explicaba desde lo más simple como, por qué lavarse las manos con jabón durante 20 segundos puede ayudar a prevenir los contagios de COVID-19. Replicar el modelo surcoreano en Italia era irrealista. Era imposible monitorear a la gente por i) motivos inherentes a la cultura, ii) no se realizaron el muestreo agresivo ni controles de temperatura exhaustivos de la población, iii) el servicio nacional de salud (público y uno de los mejores de Europa) y los recursos han sido sobrepasados por la cantidad de gente contagiada. Actualmente, hospitales privados han transformado su infrastructura y universidades e institutos de investigación biomédica han puesto a disposición sus laboratorios de biología molecular para aumentar la capacidad de tratamiento y diagnóstico respectivamente; con el fin de controlar la propagación y el número de personas que requieren tratamiento médico.

La estrategia China de contención es una combinación entre el enfoque surcoreano y el italiano. Inicialmente se instauró el monitoreo de la temperatura, el uso de mascarillas y el lavado de manos. Como resultado de la evolución y comprensión del brote epidémico, se aplicaron medidas mas agresivas basadas en la 
evi dencia científica disponible. Estas fueron suspensión de eventos y reuniones públicas, un mes de cuarentena en casa, restricción para viajar y desplazarse, uso de tecnologías como "big data" e inteligencia artificial, para facilitar la detección y el seguimiento de personas potencialmente infectadas evitando así nuevos contagios. La excepcional cobertura y adherencia a estas iniciativas fue posible gracias al profundo compromiso de la gente.

\section{Sirve un cambio de ruta}

En países como Chile, con una mentalidad similar a la italiana, resulta fundamental respetar el distanciamiento social, para evitar el colapso del sistema sanitario y las nefastas consecuencias que esto produciría. Esto no es interpretable ni menos relativo a veleidades personales. No debe ser entendido como un período de vacaciones o relajo. Esta pandemia representa una prueba seria de civilidad y responsabilidad social. En los días venideros cada uno de nosotros tiene que confiar en los datos científicos y la opinión de expertos en salud pública por sobre teorías conspirativas y el clásico oportunismo político. En Italia fue necesaria la onda expansiva de COVID-19 para que la sociedad italiana entendiera el valor del sistema nacional de salud como un bien común. Esta conciencia tardía es la virtud más inesperada del SARS-CoV-2 y un punto político de no retorno. Los países tienen el deber de hacer cambios sistémicos en sus políticas internas de distribución de recursos. Italia invierte el $1.38 \%$ de su producto interno bruto (PIB) en investigación y desarrollo científico (I\&D). Chile por su parte invierte casi cuatro veces menos, con un insignificante $0.36 \%$. No obstante, ambos países poseen cosas en común. Ambos pertenecen a la OCDE (organización para la cooperación y desarrollo), han rebajado el presupuesto en salud pública e I\&D, y están muy por debajo de lo invertido por China en estas materias. China dispone el $2.12 \%$ de su PIB, y ha puesto en evidencia, cuan valiosa resulta la inversión. Fue el trabajo de sus científicos y expertos en salud pública que sirvió para aislar el virus causante de COVID-19, establecer herramientas de diagnóstico y determinar parámetros clave de transmisión, como la ruta de propagación y el período de incubación. Queda demostraddo que el gasto en salud e I\&D es una inversión con efectos benéficos en el mediano-largo plazo.

Los políticos no pueden continuar paralizados, pensando solo en la próxima elección, con aquella pequeña visión de solo invertir recursos en aquellas cosas que "son visibles", que persiguen únicamente el rédito electoral.

Es necesario fortalecer los servicios primarios de salud, tener la infraestructura adecuada para enfrentar los desafíos que suponen las epidemias y catástrofes naturales, porque vendrán más, esto está garantizado. Es fundamental tener una fuerza de respuesta rápida -compuesta por enfermeras, matronas, médicos, bioquímicos, biólogos, epidemiólogos, expertos en modelamiento matemático tecnólogos- preparada, actualizada. No se trata solo de proveer mascarillas y vacunas, también de monitorear los patrones de la enfermedad, de asegurar a los ciudadanos la información correcta, y presentarla de la forma adecuada (no dispersa en programas de televisión). Es necesario que cada país cuente con su centro de control y detección de enfermedades (de la sigla en inglés CDC, Center for Disease Control and Prevention). En el mundo globalizado actual, es ingenuo e inútil pensar que una epidemia que emerge en un mercado localizado en una región del sur de China, no llegará y golpeará el último rincón del mundo, Chile.

Mi llamado es a no perder nuestros hábitos sociales, sólo adaptarlos y en tiempos de consignas, crear una nueva que representa, creo, al Chile actual: "distantes, pero unidos".

Cordialmente,

\section{Patricio Fuentes Bravo, Ph.D.}

Center for Genomic Science of IIT at SEMM

Istituto Italiano di Tecnologia

Milán, Italia

patricio.fuentes@ieo.it 